\title{
Effect of Application of Health Promotion Model on Lifestyle of Women with Endometriosis
}

\author{
Nesma Abd-Elaziz Ibrahim ${ }^{1}$, Moharam Abd -Elhasib El-Nafrawy ${ }^{2}$, Soad Abd-Elsalam \\ Ramadan $^{3}$, and Amira Mohamed Salama ${ }^{4}$ \\ (1) Demonstrator of Obstetrics and Woman's Health Nursing, Faculty of Nursing, Benha University, \\ (2) Professor of Obstetrics and Gynecological Medicine, Faculty of Medicine Benha University, (3) \\ Professor of Obstetrics and Woman's Health Nursing, Faculty of Nursing, Benha University, and (4) \\ lecturer of Obstetrics and Woman's Health Nursing, Faculty of Nursing, Benha University
}

\begin{abstract}
Background: Endometriosis is a life-threatening gynecological health problem in women during the reproductive age that cause chronic pelvic pain, infertility, dysmenorrhea, dyspareunia, dysuria and dyschezia. Aim: The study aimed to evaluate the effect of application of health promotion model on lifestyle of women with endometriosis. Design: Quasi-experimental study design (preposttest). Setting: The study was conducted at Obstetric and Gynecological out -patient clinic in Benha University hospital. Sample: A purposive sample consisted of 146 women with endometriosis. They divided control group comprised 73 women and study group comprised 73 women. Tools: Structured self-administered questionnaire, health promotion lifestyle profile-II and patient's satisfaction sheet. Results: $65.8 \%$ of study group were highly satisfied of health promotion model compared to only $7.2 \%$ of control group, total health promotion lifestyle profile-II improved from $20 \%$ before program implementation to $64.4 \%$ after program implementation among study group while there was no improvement in the control group, nearly three quarters of both study and control groups respectively had poor knowledge score about endometriosis before program implementation. Meanwhile, more than three quarters of study group had good knowledge score about endometriosis. Conclusion: The present study showed that there was a highly statistical significant difference regarding all health promotion lifestyle profile-II items (health responsibility, physical activity, nutrition, spiritual growth, interpersonal relations and stress management) between study and control groups after program implementation $(\mathrm{P}<0.001)$. Application of health promotion model has positive effect on lifestyle of women with endometriosis therefore, the study hypothesis was supported. Recommendation: A simplified and comprehensive booklet should be available for all patients with endometriosis which include a clear, brief and simple explanation about non pharmacological modalities to reduce endometriosis related pain.
\end{abstract}

Key words: Health promotion model, Lifestyle, Endometriosis.

\section{Introduction:}

Endometriosis is a common gynecological disorder, with a reported prevalence of $2-10 \%$ in women of reproductive age. It is defined as the presence of ectopic endometrial-like tissue, which induces a chronic, inflammatory reaction. Endometriosis often appears as lesions or cysts at several parts of the body such as pelvic organs and peritoneum which affect the physical and mental well-being and quality of life (Van Der Zanden et al., 2020).

It has been estimated that more than 176 million women worldwide suffer from endometriosis and its associated symptoms including infertility, cyclical and non-cyclical abdominal pain, dysmenorrhea, bloating, 
diarrhea or constipation dyspareunia, dysuria and dyschezia. It is generally accepted that no correlation exists between the severity of such pain symptoms and the extent of disease (Working group of ESGE et al., 2020).

The complex pathogenesis of this endometriosis remains controversial despite the most commonly suggested causes of endometriosis are retrograde menstruation, genetic predisposition, lymphatic spread, immune dysfunction, metaplasia, or environmental causes (Králíčková et al., 2020)

The symptoms of endometriosis significantly impact on a woman's work and social life. Studies showed the quality of life of women with endometriosis is seriously compromised. Social isolation is likely to occur due to personal nature of the illness as a result of unpleasant and painful symptoms. This disease also affects confidence and self-esteem impacting negatively on family and intimate relationships. There were also feelings of frustration due to inability to cope with pain making them feel miserable and sometimes depressed (Labinjo, 2020).

A variety of medical and surgical therapies are available for treatment of endometriosis and guidelines have been issued by the European Society of Human Reproduction and Embryology and the American Society for Reproductive Medicine within the past years to aid in the clinical management of this complex syndrome such as Combined oral contraceptives, gonadotropin-releasing hormone $(\mathrm{GnRH})$ agonists and Oral GnRH antagonists (Donnez et al., 2020).

Health promotion model (HPM) constructs is related to their holistic view and identification of behavioral predictors of health-promoting behaviors in lifestyle. HPM seeks mainly to help people achieve higher levels of well-being and detects underlying factors that contributes to better healthy behaviors. In fact, HPM is a descriptive model that predicts health behaviors. According to the Pender's HPM, the predicting and explaining constructs of health behaviors consist of perceived benefits of action, perceived barriers to action, action-related affect, self-efficacy, situational influences, interpersonal influences and commitment to plan of action

(Khodaveisi et al., 2020).

Nurses play a pivotal role in the delivery of high-quality holistic care to people with long-term conditions such as endometriosis. Nurse should educate the patient and to encourage self-education so that the patient may be better able to make more informed decisions about her care. A new patient visit provides an opportunity to understand the patient's journey and assess specific needs, preferences and clinical condition, thus facilitating the development of a personalized and comprehensive treatment plan that is jointly formulated (Norton \& Holloway, 2020).

\section{Significance of the study}

Worldwide the prevalence of endometriosis about 176 million and about 8.5 million women solely in the North America. Endometriosis affects reproductive aged women (5-10\%), women with subfertility (20-30\%) and women with chronic pelvic pain and infertility (40-60\%). About $70 \%$ of teens who are suffering from pelvic pain are later diagnosed with endometriosis (Akter et al., 2020).

The estimated prevalence of endometriosis is $2 \%-10 \%$ in the general population of women of childbearing age, but it can even rise up to 
$30 \%-33 \%$ in infertile women or women with chronic pelvic pain (Borghini et al., 2020). Up to $50 \%$ of women with infertility from endometriosis, $10 \%$ of women of childbearing age and $70 \%$ to $90 \%$ of women with pelvic pain have endometriosis. Furthermore, in Dakahlia Governorate, Egyptian prevalence of endometriosis in adolescents with severe dysmenorrhea was 12.3\% (Mohamed \& Hassan, 2020).

\section{Aim of the study:}

Evaluate effect of health promotion model on lifestyle of women with endometriosis.

\section{Research Hypothesis:}

Women applied of health promotion model will have better lifestyle than who didn't.

\section{Subjects and Method:}

\section{Research design:}

Quasi-experimental design (pre-post design) was utilized to fulfill the aim of this study.

\section{Setting:}

The study was conducted at Obstetric and Gynecological out -patient clinic at Benha University hospital in Benha city.

\section{Sampling:}

- Sample type: A Purposive sample.

-Sample size: The total sample was 146 women who were chosen among those attending previous setting.

\section{-Inclusion criteria:}

1-All women diagnosed with mild to moderate grade of endometriosis regardless of their age and parity. 2-Women's free from any medical or gynecological problems except endometriosis.
-Exclusion criteria:

1-Women with surgical proof of endometriosis.

2-Women with psychological or allergic diseases.

3-Women who have oncology diseases or undergoing chemotherapy.

\section{Tools for data collection:}

Three main tools were utilized for data collection:-

\section{Tool (I): A self-Administered Questionnaire:}

The researcher designed it after reviewing related literatures (O'Hara et al., 2019) under guidance of supervisors. It was written in simple Arabic language in the form of close and open- ended questions. It consisted of two parts:

\section{Part (1):}

Women personal characteristics as (age, level of education, occupation, place of residence, marital status and body mass index measurement).

\section{Part (2):}

Assessment of women's knowledge regarding endometriosis through items written in Arabic language in the form of multiple-choice questions as meaning of endometrium, concept, risk factors and causes of endometriosis. Factors that determine the stage a woman suffers from endometriosis

\section{Knowledge scoring system:-}

All knowledge variables were weighted according to items included in each question. Each item was given a score (2) when the answer was complete correct answer, a score (1) when the answer was incomplete correct answer and a score (0) when the answer was (I don't know). The total score was calculated by summation of 
the scores of its items. The total score for the knowledge of each woman was calculated by the addition of the total score of all parts. The score of total knowledge was classified as the following:

- Good when the total score was $75 \%$ to $100 \%$

- Average when the total score was $50 \%$ to less than $75 \%$.

- Poor when the total score was less than $50 \%$.

Tool II: Health Promotion Lifestyle Profile-II: was adopted From Kuan et al ., (2019). It was used to measure healthpromoting behavior. The Health Promoting Lifestyle Profile II (HPLP - II) questionnaire has been translated into different languages, including Spanish, Japanese, Arabic, Chinese, Turkish and its validity and reliability have been verified. HPLP - II is based on Pender's Health Promotion Model, HPLP-II conceptualizes an individual's health-promoting lifestyle. It composed of 50 items and six subscales: Health responsibility, physical activity, nutrition, spiritual growth, interpersonal relationship, stress management).

\section{Scoring system:}

These items were based on a 4-point Likert scale with four possible responses: 1 (never), 2 (sometimes), 3 (often), and 4 (routinely). The total score of healthpromoting lifestyle was obtained by calculating the mean of responses to all the 50 items. In addition, the total score of each subscale was computed by calculating the mean of responses to that subscale's items. In addition, the total score of each subscale was computed by calculating the mean of responses to that subscale's items. Overall, HPLP-II scores range from

-Good when the total score was $>75 \%$.
-Fair when the total score was $50-<75 \%$. -Poor when the total score was $<50 \%$.

Tool III: Patient's Satisfaction Sheet: was adopted from Singer et al., (1998). The visual analog satisfaction scale was an instrument in which 0 (zero) represented that the sample was unsatisfied with the health promotion model implementation and 10 fully satisfied.

\section{Scoring system:}

$$
\begin{aligned}
& 0=\text { Unsatisfied } \\
& 1-9=\quad \text { Satisfied }
\end{aligned}
$$

Highly satisfied $=10$.

\section{Tools Validity:}

The validity of questionnaire was reviewed by 3 jury experts in the field of obstetrics $\&$ woman health nursing to ascertain clarity, relevance, comprehensiveness and applicability of tools. Modifications were done such as adding, rephrasing and omitting some questions.

\section{Tools reliability:}

Reliability was done by Cronbach's alpha, the internal consistency of knowledge of study group equal 0.79 ,control group equal 0.29 , health promoting lifestyle profile II of study group equal 0.55 and control group equal 0.792 .

\section{Ethical Considerations:}

An official permission from the selected study setting was obtained for the fulfillment of the study. Before applying the tools, the researcher explained the aim and importance of the study to gain women's confidence and trust. The researcher took oral consent from women to participate in the study and confidentialities were assured. The data were collected and treated confidentially where personal data were not disclosed and the women were assured that all data was 
used only for research purpose. The women were free to withdraw from study at any time. The study wasn't having any physical, social or psychological risk on the participants.

\section{Pilot study}

The pilot study was conducted on $10 \%$ of the total sample (15 women) before starting data collection to estimate the time required for completing the sheets and to check the simplicity, clarity, applicability and feasibility of the developed tools. No modifications were done. Thus, women involved in the pilot study were included in the study sample.

\section{Field work}

The study was carried out from June 2020 to August 2020, covering six months. The researcher visited the pre mentioned setting from 9 am to $3 \mathrm{pm}$, three days per week (Sunday, Tuesday and Thursday) until the predetermined size of sample was completed.

\section{Preparatory phase:}

It was the first phase of the study and it included reviewing current and related literatures. Also, theoretical knowledge of various aspects of the study using books, articles, periodicals, magazines and internet to develop tools for data collection.

\section{Assessment phase:}

This phase encompassed interviewing women to collect baseline data. At the beginning of interview the researcher introduced herself, greeted each woman, explained the aim of the study, scheduled times and frequency of sessions to selected women to assure adherence to selected interventions. The researcher took oral consent from women to participate in the study.
The researcher distributed, selfadministrated questionnaire (Appendix I) to collect personal data, socio-demographic characteristics and women's knowledge regarding endometriosis. The average time required for completion of the questionnaire was around (15-20 minutes).

Then the researcher distributed, health promoting lifestyle profile II questionnaire (Appendix II) (Pretest) to collect the lifestyle data of women. The average time required for completion of the questionnaire was around (10-15 minutes).

The interviewing process was done on 3 days/ week starting from 9 to $12 \mathrm{pm}$. Each woman was interviewed individually. The number of interviewed women per week was 9-15 women (3-5 women/day). The average time taken for completing each sheet was around 25-35 minutes depending on the response of the women. Each woman was reassured that obtained information will be confidential and used only for the purpose of the study.

\section{Planning Phase:}

The program was conducted to determine effect of application of health promotion model on lifestyle of women with endometriosis. Participants (study group) were classified to 5 groups, each group consisted of 14-15 women). The researcher and participants attended data collection site for three times/ week (Sunday, Tuesday and Thursday). The duration of the educational program lasted 4 weeks for each group. Program was classified into 4 sessions each session was planned to provide specific information about endometriosis (symptoms, causes, risk factors, investigation and treatment) and healthy life style for women of endometriosis through three main components; (diet, exercise and stress management) using booklet, Actual time of 
each session was 40-60 minutes. These sessions were applied in the waiting area of Obstetric and Gynecological out -patient clinic at Benha University hospital.

Telephone number was obtained from women to facilitate contact in cases women did not attended their planned program schedule.

\section{Implementation Phase (visits 2-3)}

The researcher followed up women in study group and applied program using health promotion model technique. 73 women (divided equally into five groups) attended the educational program through 4 sessions. At the beginning of each session, the researchers started by giving a summary about the previous session and explaining the objective of the new one, using simple Arabic language to suit women' level of understanding.

Orientation session: included providing women knowledge about endometriosis, its cause, risk factors, signs \& symptoms, impact of endometriosis on women quality of life and different management modalities for endometriosis.

First session: concerned with diet included use different methods as example for daily meals, Visual aid "illustrated pictures", and discussion. Women instructed to follow healthy nutritional habits (food rich with Omega3, fruits, and vegetables that have anti-inflammatory, anti-oxidant, and antiestrogen effect).

Second session: was focused on exercises included explained different types of exercises that performed by woman "as walking, jogging, cycling, aerobics and gymnastics. On this instruction session used different methods as role play, demonstration and re-demonstrations. Women instructed to perform $30 \mathrm{~min}$ of moderate intensity aerobic activity as walking at least five days per week.

Third session: included pain and stress management. Women taught several methods to relieve pain including heat and massage for relieving dysmenorrhea. In addition to, increase amount of foreplay, use alternative sexual position to decrease dyspareunia. While, stress management will consist of instruction for yoga, breathing exercises, and engaging in support group. The researcher gave women the educational booklet at the end of sessions.

\section{Break phase:}

The researcher-contacted women in study group by phone to ensure that they followed the guideline and applied the provided care effectively. The researcher provided any required advice or care to women during break.

Control group women followed by phone to avoid their drop out from the study, but no care provided to women during break to prevent study bias.

\section{Evaluation phase:}

After two months of implementation of the program the posttest applied to evaluate women's knowledge regarding endometriosis and the lifestyle of women through use of endometriosis assessment tool(Appendix I), HPLPII (Appendix II) and the researcher distributed the satisfaction sheet among women (Appendix III) to evaluate degree of their satisfaction for both study and control groups. The researcher gave booklets to women in control group. Finally, the researcher compared pretest and posttest results of the two groups to evaluate the effectiveness of the program implementation.

\section{Statistical design:}

Data were verified prior to computerized entry. The Statistical Package 
for Social Sciences (SPSS version 21.0) was used for that purpose, followed by data tabulation and analysis. Descriptive statistics were applied (e.g., mean, standard deviation, frequency and percentages). Independent tResults:

Table (1) clarifies that, less than half $(45.2 \%$ $\& 41.1 \%$ ) of both study and control groups respectively in age group (20 - > 30 years) and (30 - > 40 years) with a mean age of $29.76 \pm 6.79$ years and $29.75 \pm 7.31$ years respectively. Majority $(90.4 \%$ \& $83.6 \%)$ of the study group and control group were lived in urban area respectively. Concerning level of education, it was clear that half of both study group and control group (50.7\%) had secondary education. As regards marital status, majority of study group $(93.2 \%)$ and nearly half of control group $(50.7 \%)$ were married. According to occupation more than three quarters of both study \& control group $(80.8 \%$ \& $68.5 \%)$ respectively were employee. Additionally there was no statistical significance difference between study and control groups regarding socio demographic characteristics.

Figure (1) shows that, nearly three quarters of both study and control groups $(72.6 \%$ $\& 71.2 \%$ ) respectively had poor knowledge score about endometriosis before program implementation. Meanwhile, more than three quarters $(61.6 \%)$ of study group had good knowledge score about endometriosis and only (15.1\%) of control group had good knowledge score about endometriosis after program implementation.

Table (2) reveals that, there was no a statistically significant difference between test, Chi-square test and Pearson correlation coefficients were used. A significant level value was considered when $p \leq 0.05$. And a highly significant level value was considered when $\mathrm{p}<0.001$.

study and control groups regarding all items of health promotion lifestyle profile-II before program implementation $(\mathrm{P}=>0.05)$. Meanwhile, there was a highly statistical significant difference regarding all health promotion lifestyle profile-II items after program implementation $(\mathrm{P}=<0.001)$.

Figure (2) reveals that, total health promotion lifestyle profile-II improved from (20\%) before program implementation to (64.4\%) after program implementation among study group while there was no improvement in the control group.

Table (3) shows that, there was no statistically significant correlation between total knowledge and total health promotion lifestyle profile-II of both study and control group before program implementation. On the other hand there was highly statistical significant correlation between total knowledge and total health promotion lifestyle profile-II in study group. While there was no statistically significant correlation between total knowledge and total health promotion lifestyle profile-II among control group after program implementation.

Figure (3) shows that, nearly two thirds $(65.8 \%)$ of study group were highly satisfied of health promotion model compared to only (7.2\%) of control group. 
Table (1): Distribution of studied sample according to demographic characteristics $(n=146)$.

\begin{tabular}{|c|c|c|c|c|c|c|}
\hline \multirow[t]{2}{*}{$\begin{array}{l}\text { Demographic } \\
\text { characteristics }\end{array}$} & \multicolumn{2}{|c|}{$\begin{array}{c}\text { Study group } \\
(\mathrm{n}=73)\end{array}$} & \multicolumn{2}{|c|}{$\begin{array}{c}\text { Control group } \\
(n=73)\end{array}$} & \multirow[t]{2}{*}{$\overline{X^{2}}$} & \multirow[t]{2}{*}{ p-value } \\
\hline & No & $\%$ & No & $\%$ & & \\
\hline \multicolumn{7}{|l|}{ Age ( years) } \\
\hline$>20$ years & 3 & $4.1 \%$ & 6 & $8.2 \%$ & \multirow{5}{*}{2.104} & \multirow{5}{*}{.551} \\
\hline $20->30$ years & 33 & $45.2 \%$ & 30 & $41.1 \%$ & & \\
\hline $30->40$ years & 33 & $45.2 \%$ & 30 & $41.1 \%$ & & \\
\hline$<40$ years & 4 & $5.5 \%$ & 7 & $9.6 \%$ & & \\
\hline Mean \pm SD & \multicolumn{2}{|c|}{$29.76 \pm 6.79$} & \multicolumn{2}{|c|}{$29.75 \pm 7.31$} & & \\
\hline \multicolumn{7}{|l|}{ Residence } \\
\hline Rural & 7 & $9.6 \%$ & 12 & $16.4 \%$ & \multirow{2}{*}{1.513} & \multirow{2}{*}{.219} \\
\hline Urban & 66 & $90.4 \%$ & 61 & $83.6 \%$ & & \\
\hline \multicolumn{7}{|l|}{ Education } \\
\hline Read and write & 10 & $13.7 \%$ & 13 & $17.8 \%$ & \multirow{4}{*}{0.575} & \multirow{4}{*}{.750} \\
\hline Primary education & 0 & $0.0 \%$ & 0 & $0.0 \%$ & & \\
\hline Secondary education & 37 & $50.7 \%$ & 37 & $50.7 \%$ & & \\
\hline University education & 26 & $35.6 \%$ & 23 & $31.5 \%$ & & \\
\hline \multicolumn{7}{|l|}{ Marital status } \\
\hline Single & 2 & $2.7 \%$ & 5 & $6.8 \%$ & \multirow{4}{*}{1.977} & \multirow{4}{*}{.372} \\
\hline Married & 68 & $93.2 \%$ & 63 & $50.7 \%$ & & \\
\hline Divorced & 3 & $4.1 \%$ & 5 & $6.8 \%$ & & \\
\hline Widowed & 0 & $0.0 \%$ & 0 & $0.0 \%$ & & \\
\hline \multicolumn{7}{|l|}{ Occupation } \\
\hline House wife & 14 & $19.2 \%$ & 23 & $31.5 \%$ & \multirow[t]{2}{*}{2.932} & \multirow[t]{2}{*}{.087} \\
\hline Employee & 59 & $80.8 \%$ & 50 & $68.5 \%$ & & \\
\hline
\end{tabular}

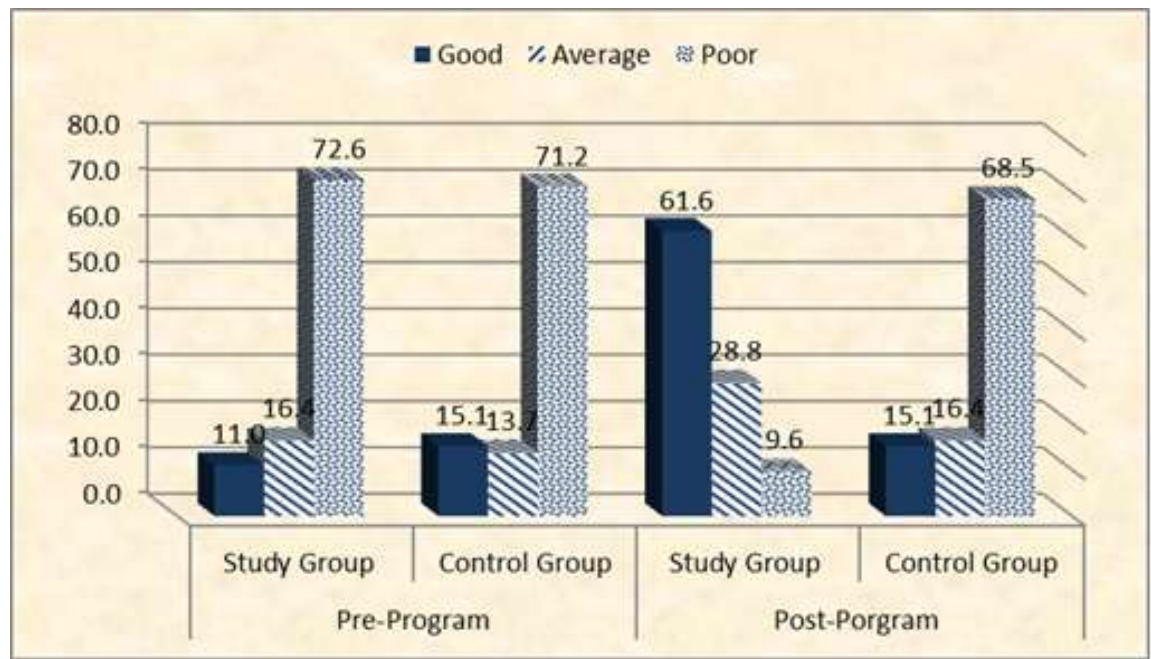

Figure (1): Distribution of studied sample according to total knowledge scores about endometriosis before and after program implementation 
Table (2): Distribution of studied sample regarding health promotion lifestyle profile-II $(n=146)$.

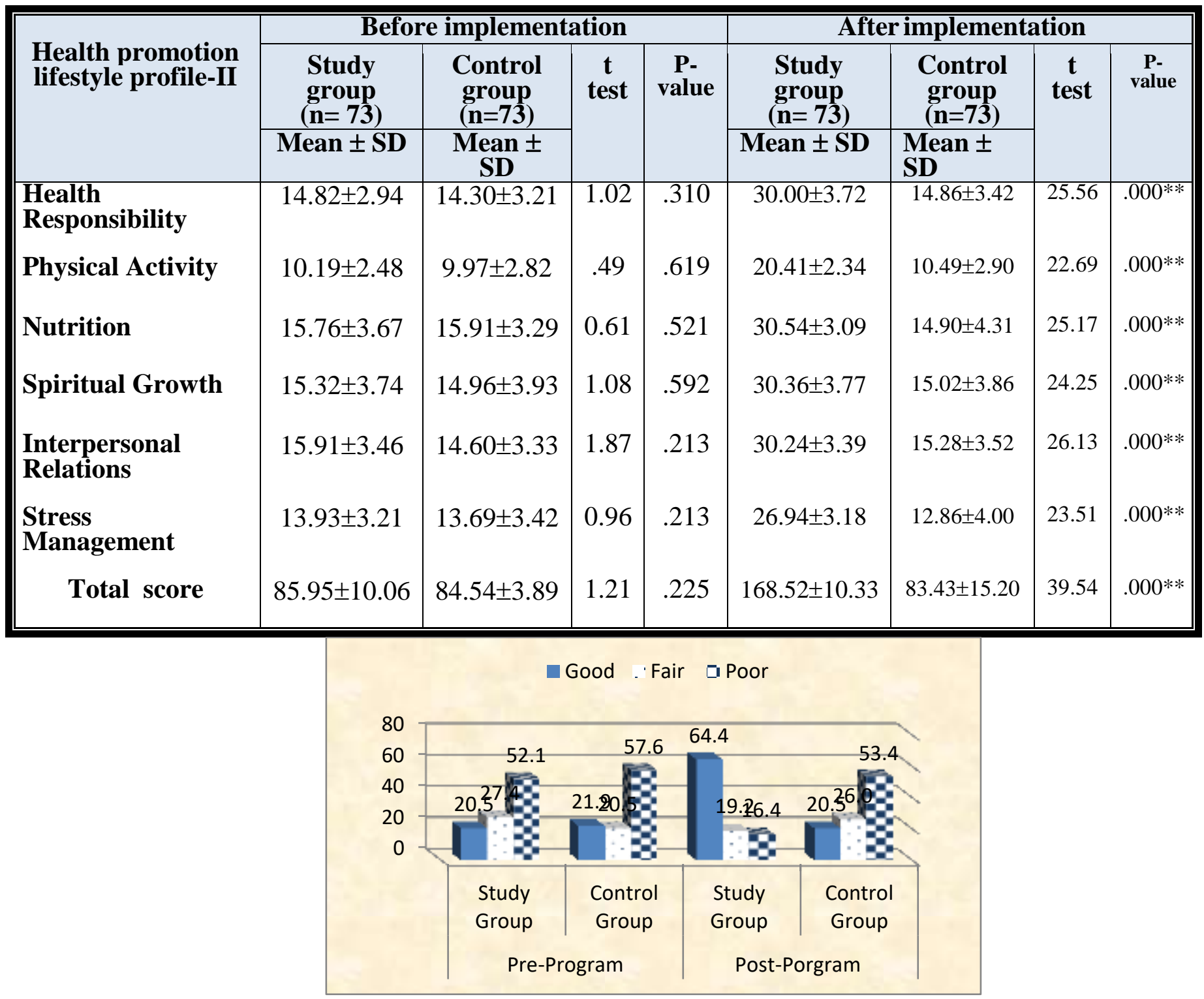

Figure (2): Distribution of studied sample regarding total health promotion lifestyle profile-II before and after program implementation.

Table (3): Correlation between total knowledge and total health promotion lifestyle profileII of studied sample before and after program implementation $(n=146)$.

\begin{tabular}{|c|c|c|c|c|c|c|c|c|c|}
\hline \multirow{4}{*}{ Variable } & & \multicolumn{8}{|c|}{ Total knowledge scores } \\
\hline & & \multicolumn{4}{|c|}{$\begin{array}{c}\text { Study group } \\
(\mathrm{n}=73)\end{array}$} & \multicolumn{4}{|c|}{$\begin{array}{c}\text { Control group } \\
(n=73)\end{array}$} \\
\hline & & \multicolumn{2}{|c|}{ Before } & \multicolumn{2}{|c|}{ After } & \multicolumn{2}{|c|}{ Before } & \multicolumn{2}{|c|}{ After } \\
\hline & & $\mathbf{r}$ & $\mathbf{p}$ & $\mathbf{r}$ & $\mathbf{P}$ & $\mathbf{r}$ & $\mathbf{p}$ & $\mathbf{r}$ & $\mathbf{P}$ \\
\hline \multirow{2}{*}{$\begin{array}{l}\text { Total health promotion } \\
\text { lifestyle profile-II }\end{array}$} & Before & 0.14 & 0.21 & & & 0.02 & 0.83 & & \\
\hline & After & & & 0.68 & $0.004 *$ & & & 0.21 & 0.06 \\
\hline
\end{tabular}




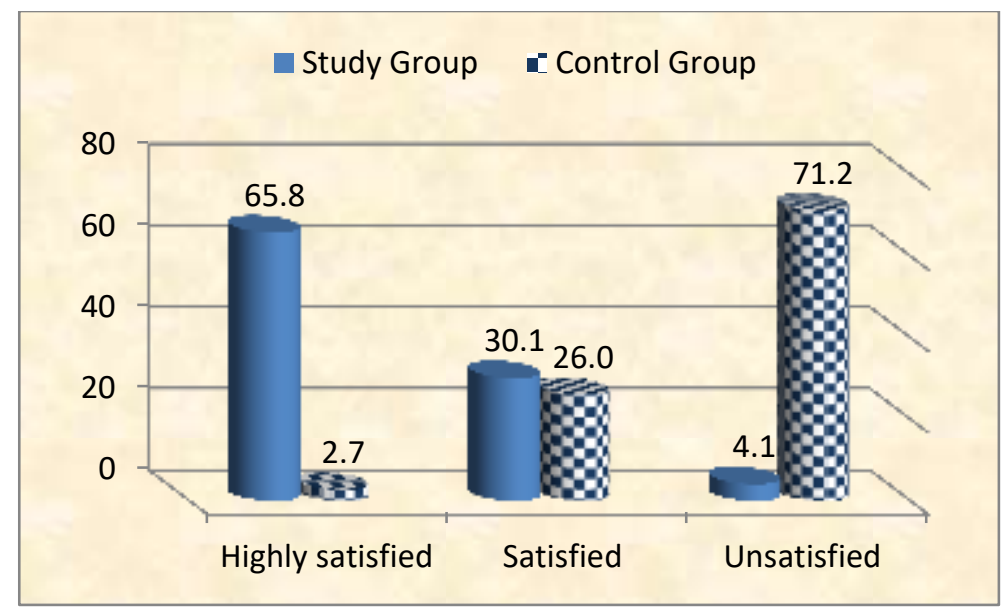

Figure (3): Distribution of study and control groups regarding satisfaction of health promotion model

\section{Discussion:}

Endometriosis is an estrogendependent gynecological disorder that affects at least $10 \%$ of women of reproductive age. It causes long-term chronic pelvic pain, dysmenorrhea, severe dyspareunia, infertility and pelvic-organ dysfunction. Endometriosis profoundly impairs the quality of life of the patients with a negative impact on social and family life (Méar et al., 2020). Health promotion model (HPM) is effective in reducing risk factors, symptoms specifically in chronic diseases and promotes a healthy lifestyle(Moshki et al., 2020). It conceptualizes an individual's healthpromoting lifestyle in terms of the following dimensions; health responsibility, physical activity, nutrition, spiritual growth, interpersonal relations and stress management (Kuan et al., 2019).

The present study aimed to evaluate the effectiveness of application of health promotion model on lifestyle of women with endometriosis. It will be discussed under the following sections, general characteristics of the studied groups, knowledge of study and control groups regarding endometriosis before and after program implementation, health promotion lifestyle profile II before and after program implementation, correlation between total knowledge and total health promotion lifestyle profile II of study and control groups before and after program implementation.

Regarding personal characteristics of the studied groups, the result of the present study showed that there was no statistical significance difference between study and control groups regarding socio demographic characteristics (age, residence, educational level, marital status and occupation). This may be due to homogeneity of the study population.

This result was similar to Metwally \& Desoky, (2018) who studied" improving quality of life among women with endometriosis: an intervention study, Zigzag, Egypt "revealed that there was no statistical significant difference regarding socio-demographic characteristics between both groups.

This result was supported with ElMaraghy et al, (2017) who studied" the impact of endometriosis symptoms on health related quality of life and work productivity in Cairo, Egypt" found that there was no statistical significant differences regarding 
socio-demographic characteristics between both groups.

This result was in the same line with Abd El-Kader et al, (2019) who studied" the impact of endometriosis-related adhesions on quality of life among infertile women, Zigzag, Egypt " showed that there was no statistically significant difference between studied groups regarding age, BMI, educational level and occupation.

Age is the most important factor that affects health of women. In the present study, less than half of both study and control groups respectively in age group (20 - > 30 years) and (30 - > 40 years) with a mean age of $29.76 \pm 6.79$ years and $29.75 \pm 7.31$ years respectively. Results of the current study could positively impact on the women information due to the young age of women because they had an opportunity to interact with the researcher and they had greatest ability to acquire more information.

Majority of the study group and control group were lived in urban area respectively. This may be due to that women living in urban areas have high level of knowledge and have the opportunity to tell about endometriosis.

Concerning level of education, it was clear that half of both study group and control group had secondary education.

From my point of view level of education might affect the size of their information because scientific level increased, the bulk of knowledge must be increased. In addition to serve the study because they were able to understand and apply the program well.

As regards marital status, majority of study group and nearly half of control group were married and according to occupation more than three quarters of both study \& control group respectively were employee.

These findings were in harmony with Yousif et al., (2019) who studied" implemented nursing strategy based on health promotion model for alleviating endometriosis relating symptoms, Egypt" illustrated that the mean age of the women of study and control group respectively were $(28.14 \pm 3.92 \& 27.23 \pm 4.56$ years $)$, nearly half of the studied women on both groups had secondary education. Most of the studied women on both groups were lived in urban area. Most of studied women on both groups were married .Most of studied groups on both groups were worked. As well mentioned that no statistical difference between women on both groups as regard socio demographic characteristics. This may be explained by researcher as two studies involve nearly same criteria.

This result of the current study came in agree with Ghonemy and El Sharkawy, (2017) who conducted a quasi-experimental study under a title "impact of changing lifestyle on endometriosis related pain, Cairo, Egypt" reported that about women age ranged between 19-39 years old with mean of $(29.8 \pm 4.02)$. More than three quarters of the women had completed technical secondary school education. More than half of women lived in urban area. More than half of them were married.

The result of the current study disagreed with Sayed and Aboud, (2018) who studied " effect of an educational intervention on quality of life and sexual Function in women with Endometriosis, Benha, Egypt" indicated that the mean age of the study and control groups was (32.29 \pm $2.58 \& 31.54 \pm 2.91$ ) respectively. More 
than three quarters of both groups lived in rural area and more than half of both groups respectively were housewives. Additionally agree with there was no statistically significant difference between both groups regarding demographic characteristics. Less than two thirds of both groups had a secondary education.

Regarding total knowledge score of the studied groups, the present study indicated that nearly three quarters of both study and control groups respectively had poor knowledge score about endometriosis before program implementation. Meanwhile, more than three quarters of study group had good knowledge score about endometriosis and only (15.1\%) of control group had good knowledge score about endometriosis after program implementation. This may be due to women's active participation and good communication with researcher besides educational guideline that plays a very important role in helping woman to acquire knowledge about endometriosis.

This result was consisted with Abd El-Mouty et al., (2016) who studied "raising awareness of working women in Mansoura university towards endometriosis: a follow up study, Egypt" stated that there was a significant increase in the average score of knowledge at post educational session and at follow up time compared to their average knowledge score before educational session.

Concerning mean total score of health promoting lifestyle profile-II before and after program implementation, the result of current study clarified that there was no a statistically significant difference between study and control groups regarding all items of health promotion lifestyle profile-II before program implementation $(\mathrm{P}>0.05)$. Meanwhile, there was a highly statistical significant difference regarding all health promotion lifestyle profile-II items after program implementation $(\mathrm{P}<0.001)$. This result confirmed the achievement of current research hypothesis. These finding may be due to support healthy behavior is the main goal of health promotion and healthy behavior is a result of a multidimensional approach (healthy nutrition, physical exercise, social \& psychological support) (Leischik et al, 2016).

The results of current study were supported by Yousif et al., (2019) showed that there is a highly statistical significant improvement on total score and subtotal score of health promotion lifestyle profile-II five domains post intervention and at follow-up on intervention group. Conversely, the improvement on all score and subtotal score on control group was not significant.

This result was in agreement with Ghonemy and El Sharkawy, (2017) pointed out that health education about changing lifestyle particularly dietary health education for women with endometriosis have shown beneficial improvement of knowledge and reduction endometriosis related pain.

The result of current study showed that total health promotion lifestyle profileII improved from (20\%) before program implementation to $(64.4 \%)$ after program implementation among study group while there was no improvement in the control group. This may be due to implementing health promotion lifestyle profile II so health promotion model had a positive effect on lifestyle of women with endometriosis. This 
result confirmed the achievement of current research hypothesis (Application of health promotion model will have a positive effect on lifestyle of women with endometriosis. Women who received application of health promotion model will have better lifestyle than who don't).

The result of current study clarified that there was no statistically significant correlation between total knowledge and total health promotion lifestyle profile-II of both study and control groups before program implementation. On the other hand there was highly statistical significant correlation between total knowledge and total health promotion lifestyle profile-II in study group. While there was no statistically significant correlation between total knowledge and total health promotion lifestyle profile-II among control group after program implementation.

From researcher point of view, the implementation of health promotion lifestyle profile II based on health promotion model help women to acquire knowledge of how to adapt with endometriosis through promoting their healthy behavior that enable them to modify lifestyle and also increase their satisfaction as the results of the current study revealed that nearly two thirds of study group were highly satisfied of health promotion model. So health promotion model had positive effect on lifestyle of women with endometriosis.

In the view of the above mentioned findings, hypothesis which stated that "women who received health promotion model will have better lifestyle than who don't " was supported.

\section{Conclusion:}

Application of health promotion model had a positive effect on knowledge and lifestyle of women with endometriosis. There was a highly statistical significant difference regarding knowledge and all health promotion lifestyle profile-II items (health responsibility, physical activity, nutrition, spiritual growth, interpersonal relations and stress management) between study and control groups after program implementation $(\mathrm{P}<0.001)$. Moreover, the women in study group showed a significant improvement in knowledge and lifestyle, on the other hand control group showed minimal or no changes. Also, there was highly statistical significant correlation between total knowledge and total health promotion lifestyle profile-II in study group. Therefore, the study hypothesis was supported.

\section{Recommendations:}

- A simplified and comprehensive booklet should be available for all patients with endometriosis which include a clear, brief and simple explanation about non pharmacological modalities to reduce endometriosis related pain.

- Educational program for women to raise their awareness about endometriosis related factors should be a priority to ensure early diagnosis of the disease.

- Activate training programs for nurses to raise their knowledge and improve their attitude about endometriosis.

- Replication of the study on large sample size in different setting. 


\section{References:}

Abd El-Kader, A. I., Gonied, A. S., Mohamed, M. L., \& Mohamed, S. L. (2019). Impact of endometriosis-related adhesions on quality of life among infertile women. International Journal of Fertility \& Sterility. 13(1): 72-76.

Abd El-Mouty, S. M., Al_Wehedy, A., \& Hassan, S. I.(2016) .Raising awareness of working women in Mansoura University towards endometriosis: a Follow up Study. IOSR Journal of Nursing and Health

Science 5(5):15-23.

Akter, S., Xu, D., Nagel, S. C., Bromfield, J. J., Pelch, K. E., Wilshire, G. B., \& Joshi, T. (2020). GenomeForest: An Ensemble Machine Learning Classifier for Endometriosis. AMIA Summits on Translational Science Proceedings. 20(20): $33-42$.

Borghini, R., Porpora, M. G., Casale, R., Marino, M., Palmieri, E., Greco, N., \& Picarelli, A. (2020). Irritable Bowel Syndrome-Like Disorders in Endometriosis: Prevalence of Nickel Sensitivity and Effects of a Low-Nickel Diet. An Open-Label Pilot Study.Nutrients. 12(2):1-14.

Donnez, J., Taylor, H. S., Taylor, R. N., Akin, M. D., Tatarchuk, T. F., Wilk, K., \& Bestel, E. (2020). Treatment of endometriosis-associated pain with linzagolix, an oral gonadotropin-releasing hormone-antagonist: a randomized clinical trial. Fertility and Sterility.114(1):44-55.

El-Maraghy, M., Labib, K., El-Din, W.S., \& Ahmed, A.B. (2017). The impact of endometriosis symptoms on health related quality of life and work productivity in Egypt. Austin J Obstet Gynecol. 4(3): 1078-1086.

Ghonemy, G. E., \& El Sharkawy, N. B. (2017). Impact of changing lifestyle on endometriosis related pain. IOSR Journal of Nursing and Health Science (IOSRJNHS). 6(2):120-129.

Khodaveisi, M., Jafari, A., Omidi, A., Roshanaei, G., \& Sazvar, A. (2020). The effect of a Pender's health promotion model-based educational intervention on physical activity in office staff. Sport Sciences for Health. 16(1), 31-38.

Králíčková, M., Laganà, A. S., Ghezzi, F., \& Vetvicka, V. (2020). Endometriosis and risk of ovarian cancer: what do we know?. Archives of gynecology and obstetrics. 301(1), 1-10.

Kuan, G., Kueh, Y. C., Abdullah, N., \& Tai, E. L. M. (2019). Psychometric properties of the health-promoting lifestyle profile II: cross-cultural validation of the Malay language version. BMC public health. 19(1): 1-10.

Labinjo, T. (2020). A Review of the Prevalence of Endometriosis in African Women. J Womens Health. Issues Care 9, (4): 1-4.

Leischik, R., Dworrak, B., Strauss, M., Przybylek, B., Schöne, D., Horlitz, M., \& Dworrak, T. (2016). Plasticity of health. German Journal of Medicine. 1, 117.

Méar, L., Herr, M., Fauconnier, A., Pineau, C., \& Vialard, F., (2020): Polymorphisms and endometriosis: a systematic review and meta-analyses. Human Reproduction Update. 26(1): 73103. 
Metwally, H. M. S., \& Desoky, M. M. A. M., (2018): Improving quality of life among women with endometriosis: an intervention study. American Journal of Nursing. 6(6): 668-678.

Mohamed, W., \& Hassan, H. (2020). Effect of instructional supportive guideline for improving women's awareness towards endometriosis. American journal of nursing research.8(1): 38-47.

Moradi, M., Parker, M., Sneddon, A., Lopez, V., \& Ellwood, D., (2014): Impact of endometriosis on women's lives: a qualitative study. BMC women's health. 14(1): 1-12.

Moshki, M., Mohammadipour, F., Gholami, M., Heydari, F., \& Bayat, M. (2020). The evaluation of an educational intervention based on Pender's health promotion model for patients with myocardial infarction. International Journal of Health Promotion and Education, 58 (4):1-13.

Norton, W., \& Holloway, D. (2020). Understanding the NICE guidance on endometriosis. Practice nursing. 31(1): 816.

O'Hara, R., Rowe, H., \& Fisher, J. (2019). Self-management in conditionspecific health: a systematic review of the evidence among women diagnosed with endometriosis. BMC women's health. 19(1): 1-19.
Sayed, H. A. E., \& Aboud, S. A. H. H. (2018). Effect of an educational intervention on quality of life and sexual function in women with endometriosis. International Journal of Studies in Nursing. 3(2): 1-`13.

Singer, A.J., and Thode, J.R., (1998). Determination of the minimal clinically significant difference on a patient visual analog satisfaction scale. Acad Emerg Med. 5:1007-11.

Van Der Zanden, M., Teunissen, D. A., Van Der Woord, I. W., Braat, D. D., Nelen, W. L., \& Nap, A. W. (2020). Barriers and facilitators to the timely diagnosis of endometriosis in primary care in the Netherlands. Family Practice. 37(1): 131-136.

Working group of ESGE, ESHRE, and WES, Keckstein, J., Becker, C. M., Canis, M., Feki, A., Grimbizis, G. F., ... \& De Wilde, R. L. (2020). Recommendations for the surgical treatment of endometriosis. Part 2: deep endometriosis. Human Reproduction Open. 2020(1):1-25.

Yousif, A. M., Abdallah, W. G., \& Mahmoud, H.. (2019). Implemented nursing strategy based on health promotion model for alleviating endometriosis relating symptoms. International Journal of Novel Research in Healthcare and Nursing. 6(3):332-344. 
اثرتطبيق نموذج تعزيز الصحة علي نمط حياة السيدات التي تعاني من بطانة الرحم المهاجرة

نسمة عبد العزيز ابرهيم- محرم عبد الحسيب النفراوي- سعاد عبد السلام رمضان- أميرة محمد سلامة

تتصف بطانة الرحم المهاجرة بوجود نسيج شبيه ببطانة الرحم خارج الرحم ،ويبلغ معدل الإصابة ببطانه الرحم المهاجرة حوالي 7ـ • ( ٪ بين النساء في سن الإنجاب. لذلك هدفت هذه الدراسة إلى تقييم تاثثر تطبيق نموذج تعزيز الصحة على نمط حياة السيدات التي تعاني من بطانة الرحم المهاجرة. وقد أجريت الدراسة في العيادة الخارجية لأمر اض النساء و التوليد بمسنتفى جامعة بنها على 7 ـ إيدة تعاني من بطانة الرحم المهاجرة. حيث كثنت النتائج عن تطبيث نموذج تعزيز الصحة له تأثير إيجابي على معلومات ونمط حياة السيدات التي تعاني من بطانة الرحم المهاجرة. كما أوصت الدر اسة بتوفير كتيب مبسط وشامل لجميع مرضى بطانة الرحم المهاجرة يتضمن شرحًا واضحًا ومختصرًا وبسيطًا عن الأساليب غير الدوائية لتقليل الألم المرتبط ببطانة الرحم المهاجرة. 